\title{
Spatial and temporal variability of inorganic carbon export from intertidal salt marshes
}

JoSEPH TAMBORSKI ${ }^{1,2}$, MEAGAN EAGLE GONNEEA ${ }^{3}$, KeVIN KroEger ${ }^{3}$, ZHAOIHUI AlecK WANG ${ }^{1}$, PAUL HENDERSON $^{1}$, BARRET KURYLYK ${ }^{2}$, MATTHEW CHARETTE $^{1}$

${ }^{1}$ Department of Marine Chemistry \& Geochemistry, Woods Hole Oceanographic Institution, Woods Hole, MA, 02543 (jtamborski@whoi.edu)

${ }^{2}$ Centre for Water Resources Studies, Dalhousie University, Halifax, NS B3H 4R2

${ }^{3}$ Woods Hole Coastal and Marine Science Center, U.S. Geological Survey, Woods Hole, MA 02543

Intertidal salt marsh respiration generates dissolved inorganic carbon (DIC) that is exported to the coastal ocean by tidal drainage. Variability in DIC flux and driving forces remains poorly constrained, despite recognition that these ecosystems are important in regional carbon budgets. The spatial and temporal (seasonal, annual) variability of marsh pore water exchange (PEX) and DIC export was assessed from a micro-tidal salt marsh (Sage Lot Pond, MA). Spatial variability in marsh PEX and DIC flux was constrained from sediment core ${ }^{224} \mathrm{Ra}:{ }^{228} \mathrm{Th}$ disequilibria. Disequilibrium between the more soluble ${ }^{224} \mathrm{Ra}$ and its sediment-bound parent ${ }^{228} \mathrm{Th}$ reveals significant PEX in the upper five $\mathrm{cm}$ of the marsh surface $\left(0-36 \mathrm{~L} \mathrm{~m}^{-2} \mathrm{~d}^{-1}\right)$ that is most intense in low marsh elevation zones, likely driven by tidal overtopping. Interfacial DIC transport ranges from 0.0 to $0.7 \mathrm{~g} \mathrm{C} \mathrm{m}^{-2} \mathrm{~d}^{-1}$ from these shallow sediments. Tidal pumping disproportionately impacts the marsh sediment depth horizon intersected by mean low tide, where pore water residence times are less than 10 days. PEX over this depth interval (20 $-80 \mathrm{~L} \mathrm{~m}^{-2} \mathrm{~d}^{-1}$ ) supplies seasonally variable DIC from $1.7-$ $5.4 \mathrm{~g} \mathrm{C} \mathrm{m}^{-2} \mathrm{~d}^{-1}$ that is primarily derived from sediments within $7 \mathrm{~m}$ of the tidal creek. Temporal variability in marsh PEX was constrained from 17 discrete tidal time-series of radium isotopes between 2015 and 2019 . A ${ }^{224} \mathrm{Ra}:{ }^{226} \mathrm{Ra}$ endmember mixing analysis reveals seasonal and annual fluctuations in marsh PEX driven in part by variability in mean sea level. Higher sea levels further inundate high marsh zones, increasing marsh PEX and potentially DIC export. 